\title{
Finite element analysis to assess the biomechanical behavior of a finger model gripping handles with different diameters
}

\author{
Benedict Jain A.R. Tony, Masilamany S. Alphin \\ Department of Mechanical Engineering, SSN College of Engineering, Chennai, India
}

\section{Summary}

Study aim: Interactions between the fingers and a handle can be analyzed using a finite element finger model. Hence, the biomechanical response of a hybrid human finger model during contact with varying diameter cylindrical handles was investigated numerically in the present study using ABAQUS/CAE.

Materials and methods: The finite element index finger model consists of three segments: the proximal, middle, and distal phalanges. The finger model comprises skin, bone, subcutaneous tissue and nail. The skin and subcutaneous tissues were assumed to be non-linearly elastic and linearly visco-elastic. The FE model was applied to predict the contact interaction between the fingers and a handle with $10 \mathrm{~N}, 20 \mathrm{~N}, 40 \mathrm{~N}$ and $50 \mathrm{~N}$ grip forces for four different diameter handles $(30 \mathrm{~mm}, 40 \mathrm{~mm}, 44 \mathrm{~mm}$ and $50 \mathrm{~mm}$ ). The model predictions projected the biomechanical response of the finger during the static gripping analysis with 200 incremental steps.

Results: The simulation results showed that the increase in contact area reduced the maximal compressive stress/strain and also the contact pressure on finger skin. It was hypothesized in this study that the diameter of the handle influences the stress/strain and contact pressure within the soft tissue during the contact interactions.

Conclusions: The present study may be useful to study the behavior of the finger model under the static gripping of hand-held power tools.

\section{Keywords: Finger segments - 3D finger model - Finger deformations - Contact pressure - Maximal compressive stress}

\section{Introduction}

The interaction between the hand and a physical object with the physical environment is one of the key functions of the hand grasp. In this aspect, powered and non-powered hand tools are effectively used for different work. Extended exposure of the hand and fingers to forces during industrial activities leads to musculoskeletal disorders [21]. Since the handle is an interface between the hand and the machine, an optimized handle design is a very important factor to consider in order to avoid such disorders, thereby improving the comfort. The high grip, push and pull forces and torque to the hand produce high contact pressure, which leads to cumulative trauma disorder (CTD) [11]. Operator's safety, grip strength and comfort depend on the diameter of the handles [20, 30], handle shape [21], operator's posture [12], handle surface materials [23], contact surface stiffness [25], and contact surface friction [29]. Handle diameter plays a vital role in reducing the disorders caused due to tool handles. The injury potential can be reduced by using handles with suitable diameters. The grip strength of the handle is strongly dependent on the handle diameter $[14,20]$. Hence the size of the power tool handle is considered largely by ergonomic designers to maximize the torque strength and gripping force, thereby minimizing the efforts during the power tool operations $[1,6,16,17]$.

Therefore, the finite element method has already been used by several researchers for modeling and simulating the hand, thereby determining its biomechanical behavior during different manual tasks, then evaluating the resulting loads. Stresses and deformations are an important aspect that are represented as results of the FE method within the field of ergonomics and biomechanics [15]. Numerous finger and hand models have been developed by researchers for simulating different problems. Wu et al. [34] developed a simplified two-dimensional (2D) finger tip model 
and analyzed the biomechanical responses during various loading conditions on a flat surface. The response of the soft tissues within different depths during vibration exposure has also been predicted using the 2D FEA model [35]. Dynamic strains induced within the soft tissues and the skin layer during both low and high frequencies were evaluated by Wu et al. [37]. Using the same 2D fingertip FE model various hand-handle interface materials were used with a flat contact. Simulations were performed and it was found that the hyper-elastic material lowered the contact pressure developed due to deformations [34].

Two-dimensional (2D) FE finger tip models are used by several researchers because of their simplicity. But in recent studies 3D FE finger tip models, which can provide insights into all three dimensions with better accuracy, were used. A geometrically symmetrical and simplified 3D fingertip FE model was proposed by Wu et al. [36] for simulating the dynamic loading and its responses. An index finger biomechanical model was developed by Brook et al. [8] and the model was applied to evaluate the muscle forces in the pinch grip. Anatomically realistic muscle connections and musculoskeletal parameters were included along with the finger models by Valero-Cuevas et al. [31]. The effect of the handle diameter and the handle size on the fingertip contact force was investigated using the hand model developed by Freund et al. [13]. The wholehand models developed were used to simulate the muscle loading for free movements and static gripping [26].

All these hand models and fingers are simulated using a linkage system composed of finger and joint segments connected with the muscle which does not contain skin/ subcutaneous tissues. Therefore these models cannot be used to evaluate the contact between the objects and fingers. In order to overcome this, the hybrid finger model was developed by $\mathrm{Wu}$ et al. [33]. It includes three finger segments, three joints and anatomical structures (nail, bone, and soft tissues). The hybrid finger model is used to investigate the effect of contact interaction between a finger and a cylinder handle coated with different soft material. The aim of this research is to develop a hybrid finger model and to simulate the contact interactions between finger models and handles with different diameters ( $30 \mathrm{~mm}, 40 \mathrm{~mm}, 45 \mathrm{~mm}$, and $50 \mathrm{~mm}$ ). The mechanical behavior of the finger model gripping with different diameter handles is evaluated as a result, in terms of contact pressure (CPRESS) and finger deformations.

\section{Material and methods}

\section{FE model}

The static gripping interaction responses among different diameter handles $(30 \mathrm{~mm}, 40 \mathrm{~mm}, 45 \mathrm{~mm}, 50 \mathrm{~mm})$ and the index finger model were analyzed using a threedimensional (3D) hybrid finger [33] finite element model. The FE finger model gripping with various diameter handles is shown in Figure 1. Abaqus (version 6.14) commercial software package was used for the construction of FE models. The FE index finger model consists of three segments: the proximal, middle, and distal phalanges. Each finger segment model along with the skin, subcutaneous tissues, bone and the nail were connected to the distal segment. The proximal and middle phalanges were conical frustums, whereas the distal phalanx was considered as a conical frustum connected with a hemisphere-like fingertip. Each finger segment was considered to be rotationally symmetrical.

The dimensions of the bony - segment were adopted from experimental studies [28], and the average of the scaled measurements from the subjects were used for

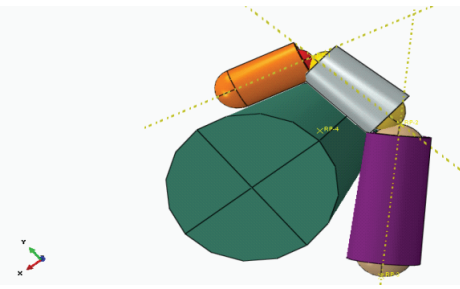

a) $30 \mathrm{~mm}$ diameter handle

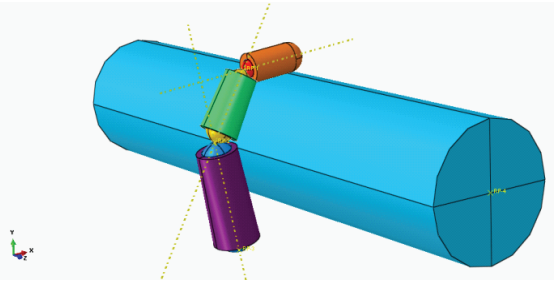

c) $45 \mathrm{~mm}$ diameter handle

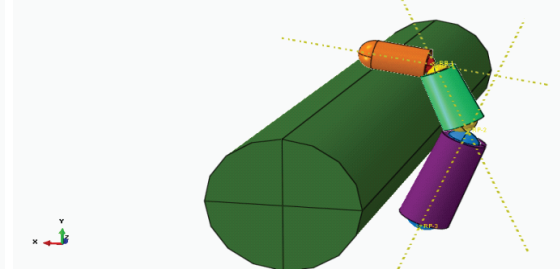

b) $40 \mathrm{~mm}$ diameter handle

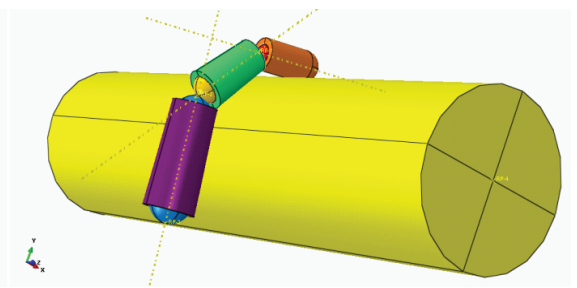

d) $50 \mathrm{~mm}$ diameter handle

Fig. 1. Finger model gripping different diameter handles (a) $30 \mathrm{~mm}$ diameter handle, (b) $40 \mathrm{~mm}$ diameter handle, (c) $45 \mathrm{~mm}$ diameter handle, (d) $50 \mathrm{~mm}$ diameter handle 
Table 1. External measurements of human phalanges from 25 subjects [28]

\begin{tabular}{|c|c|c|c|c|c|c|c|c|}
\hline \multirow{3}{*}{ Phalanx } & & \multirow{3}{*}{$\begin{array}{c}\text { Length } \\
{[\mathrm{mm}]}\end{array}$} & \multicolumn{6}{|c|}{ Diameters } \\
\hline & & & \multicolumn{3}{|c|}{ Frontal } & \multicolumn{3}{|c|}{ Sagital } \\
\hline & & & PM & MS & DM & PM & MS & $\mathrm{DM}$ \\
\hline \multirow{2}{*}{ Proximal } & Mean & 45.98 & 17.39 & 10.40 & 12.80 & 13.29 & 7.58 & 8.95 \\
\hline & $\pm \mathrm{SD}$ & 2.45 & 1.13 & 0.83 & 1.00 & 0.95 & 0.60 & 0.65 \\
\hline \multirow{2}{*}{ Middle } & Mean & 30.44 & 14.66 & 9.47 & 11.22 & 10.24 & 5.86 & 6.85 \\
\hline & $\pm \mathrm{SD}$ & 1.61 & 1.00 & 0.70 & 0.85 & 0.70 & 0.53 & 0.55 \\
\hline \multirow{2}{*}{ Distal } & Mean & 19.37 & 11.35 & 6.06 & 8.15 & 7.32 & 7.27 & 4.40 \\
\hline & $\pm \mathrm{SD}$ & 1.51 & 1.47 & 0.66 & 1.55 & 0.72 & 0.56 & 0.62 \\
\hline
\end{tabular}

PM - Proximal metaphysis; MS - Mid shaft; DM - Distal metaphysis; SD - Standard deviation.

Table 2. Internal measurements of human phalanges from 25 subjects [28]

\begin{tabular}{|c|c|c|c|c|c|c|c|c|c|c|}
\hline \multirow{3}{*}{ Phalanx } & & \multirow{2}{*}{\multicolumn{3}{|c|}{$\begin{array}{c}\text { Length } \\
{[\mathrm{mm}]}\end{array}$}} & \multicolumn{6}{|c|}{ Midshaft width } \\
\hline & & & & & \multicolumn{3}{|c|}{ Frontal } & \multicolumn{3}{|c|}{ Sagital } \\
\hline & & PM & $\mathrm{MC}$ & $\mathrm{DM}$ & UCX & RCX & $\mathrm{MC}$ & VCX & DCX & $\mathrm{MC}$ \\
\hline \multirow{2}{*}{ Proximal } & Mean & 8.76 & 27.83 & 8.09 & 2.16 & 1.96 & 6.62 & 1.53 & 1.84 & 4.23 \\
\hline & $\pm \mathrm{SD}$ & 2.49 & 3.34 & 1.17 & 0.44 & 0.67 & 1.27 & 0.30 & 0.39 & 0.91 \\
\hline \multirow{2}{*}{ Middle } & Mean & 7.53 & 15.56 & 6.10 & 1.84 & 1.81 & 5.32 & 1.21 & 1.62 & 3.00 \\
\hline & $\pm \mathrm{SD}$ & 1.12 & 2.51 & 1.16 & 0.58 & 0.62 & 1.48 & 0.29 & 0.43 & 0.70 \\
\hline \multirow{2}{*}{ Distal } & Mean & 5.43 & 7.90 & 5.45 & 1.01 & 1.10 & 3.95 & 1.13 & 0.89 & 2.33 \\
\hline & $\pm \mathrm{SD}$ & 1.29 & 1.88 & 1.24 & 0.33 & 0.30 & 0.84 & 0.39 & 0.28 & 0.50 \\
\hline
\end{tabular}

PM - Proximal metaphysis; MC - Medullary canal; DM - Distal metaphysis; UCX - Ulnar cortex; RCX - Radial cortex; VCX - Volar cortex; DCX - Dorsal cortex, SD - Standard deviation.

finger segments [33]. Table 1 and Table 2 show the internal and external measurements of human phalanges which are obtained from 25 subjects. The metacarpophalangeal joint (MCP), proximal interphalangeal joint (PIP), and distal interphalangeal joint (DIP) were used to link the proximal, middle and distal segments of the index finger model. The moment of the finger was given by each finger segment. A universal joint was modeled for the MCP joint and hinges were modeled for the PIP and DIP joints.

The end of the handle is a constraint (fixed) and the grip force was applied to the bones of each segment (distal, middle and proximal). In the current study $10 \mathrm{~N}, 20 \mathrm{~N}$, $40 \mathrm{~N}$ and $50 \mathrm{~N}$ grip forces were applied as a body force to each segment of the finger and static analysis was performed to evaluate the contact pressure and finger deformations while gripping handles of different diameters. Sensitivity analysis was performed on the model to determine the effects of varying material properties. The model parameters were estimated by least-squares fitting (using MATLAB's fminsearch). Different loads were applied to the FE model to analyze the surface magnitude and strain between the heterogeneous and homogeneous model. The sensitivity analysis parameters are in good agreement with the previous research studies' material parameters. Table 3 displays the mechanical properties which are adapted from the previous research studies from several authors $[2,4$, $5,9,32,33,38]$. In the present study, linear hexahedron mesh and element type C3D8R is used for all the models.

\section{Simulation procedure}

Three-dimensional finite element simulations were performed to evaluate the bio-mechanical behavior of the hybrid finger model and its contact interaction while gripping cylindrical handles of various diameters. In this study, $10 \mathrm{~N}, 20 \mathrm{~N}, 40 \mathrm{~N}$ and $50 \mathrm{~N}$ grip forces were applied in the hybrid finger model and analysis was performed to simulate the quasi-static gripping. The entire loading of 
Table 3. Material properties of biological components used in the FE finger model

\begin{tabular}{|c|c|c|}
\hline Material & Property & Applied \\
\hline \multirow{3}{*}{ ABS (Handle material) } & Young's modulus & $2500 \mathrm{MPa}$ \\
\hline & Poisson's ratio & 0.35 \\
\hline & Density & $1.07 \cdot 10^{-6} \mathrm{~kg} / \mathrm{mm}^{3}$ \\
\hline \multirow{3}{*}{ Bone } & Young's modulus & $17500 \mathrm{MPa}$ \\
\hline & Poisson's ratio & 0.3 \\
\hline & Density & $2 \cdot 10^{-6} \mathrm{~kg} / \mathrm{mm}^{3}$ \\
\hline \multirow{3}{*}{ Nail } & Young's modulus & $20000 \mathrm{MPa}$ \\
\hline & Poisson’s ratio & 0.3 \\
\hline & Density & $2 \cdot 10^{-6} \mathrm{~kg} / \mathrm{mm}^{3}$ \\
\hline \multirow{3}{*}{ Soft tissues distal } & Hyper-elastic material coefficients & $\begin{array}{l}\mathrm{C}_{10}=0.001704 \mathrm{MPa} \\
\mathrm{C}_{11}=0.00816 \mathrm{MPa} \\
\mathrm{D}_{1}=1 \cdot 10^{-9} \mathrm{MPa}^{-1} \\
\mathrm{D}_{2}=1 \cdot 10^{-9} \mathrm{MPa}^{-1}\end{array}$ \\
\hline & Visco-elastic parameters & $\begin{array}{l}\mathrm{g}_{1}=0.25, \mathrm{~g}_{2}=0.13, \mathrm{~g}_{3}=0.20 \\
\hat{\mathrm{o}}_{1}=0.01, \hat{\mathrm{o}}_{2}=0.40 \\
\hat{\mathrm{o}}_{3}=2.00 \mathrm{~s}\end{array}$ \\
\hline & Density & $2 \cdot 10^{-6} \mathrm{~kg} / \mathrm{mm}^{3}$ \\
\hline \multirow{3}{*}{ Soft tissues middle } & Hyper-elastic material coefficients & $\begin{array}{l}\mathrm{C}_{10}=0.001278 \mathrm{MPa} \\
\mathrm{C}_{11}=0.00612 \mathrm{MPa} \\
\mathrm{D}_{1}=1 \cdot 10^{-9} \mathrm{MPa}^{-1} \\
\mathrm{D}_{2}=1 \cdot 10^{-9} \mathrm{MPa}^{-1}\end{array}$ \\
\hline & Visco-elastic parameters & $\begin{array}{l}\mathrm{g}_{1}=0.25, \mathrm{~g}_{2}=0.13, \mathrm{~g}_{3}=0.20 \\
\hat{\mathrm{o}}_{1}=0.01, \hat{\mathrm{o}}_{2}=0.40 \\
\hat{\mathrm{o}}_{3}=2.00 \mathrm{~s}\end{array}$ \\
\hline & Density & $1.5 \cdot 10^{-6} \mathrm{~kg} / \mathrm{mm}^{3}$ \\
\hline \multirow{3}{*}{ Soft tissues proximal } & Hyper-elastic material coefficients & $\begin{array}{l}\mathrm{C}_{10}=0.001278 \mathrm{MPa} \\
\mathrm{C}_{11}=0.00612 \mathrm{MPa} \\
\mathrm{D}_{1}=1 \cdot 10^{-9} \mathrm{MPa}^{-1} \\
\mathrm{D}_{2}=1 \cdot 10^{-9} \mathrm{MPa}^{-1}\end{array}$ \\
\hline & Visco-elastic parameters & $\begin{array}{l}\mathrm{g}_{1}=0.25, \mathrm{~g}_{2}=0.13, \mathrm{~g}_{3}=0.20 \\
\hat{\mathrm{o}}_{1}=0.01, \hat{\mathrm{o}}_{2}=0.40 \\
\hat{\mathrm{o}}_{3}=2.00 \mathrm{~s}\end{array}$ \\
\hline & Density & $4 \cdot 10^{-6} \mathrm{~kg} / \mathrm{mm}^{3}$ \\
\hline
\end{tabular}

$10 \mathrm{~N}, 20 \mathrm{~N}, 40 \mathrm{~N}$ and $50 \mathrm{~N}$ was accomplished over 200 incremental steps. During the static pre-loading, joint moments were increased proportionally as a function of time. The coefficient of friction between the finger and the handle (contact interface) was considered to be 0.3 [27]. The deformations on the finger model were calculated using the static gripping of various diameter handles. The contact between the various diameter handles and the biological components (bone, skin, soft tissues) was considered. The computations for the static gripping were performed in time-domain computations.

\section{Results}

The static gripping analysis (200 incremental steps) was performed by gripping $(10 \mathrm{~N}, 20 \mathrm{~N}, 40 \mathrm{~N}$ and $50 \mathrm{~N}$ grip forces) cylindrical handles of various diameters $(30 \mathrm{~mm}$, $40 \mathrm{~mm}, 44 \mathrm{~mm}$ and $50 \mathrm{~mm}$ ) using the hybrid finger FE model. The finger deformations, maximum compressive stress, maximum compressive strain and the contact pressure distributions were calculated using static simulations. Figure 2 shows the maximal compressive stress in the soft 


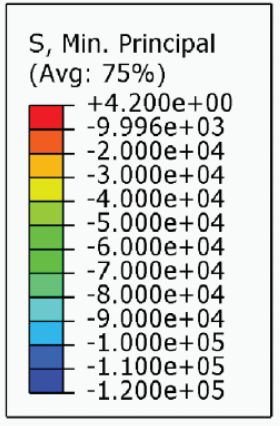

(a) $30 \mathrm{~mm}$ diameter handle

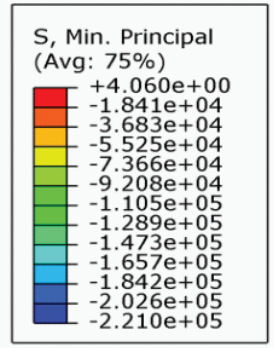

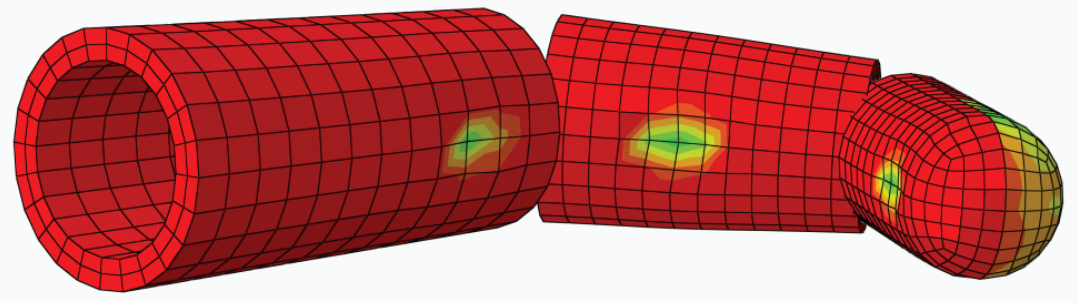

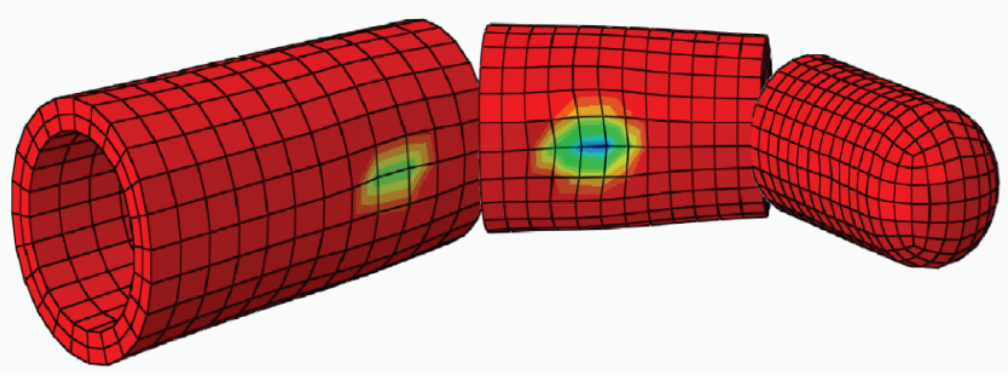

(b) $40 \mathrm{~mm}$ diameter handle

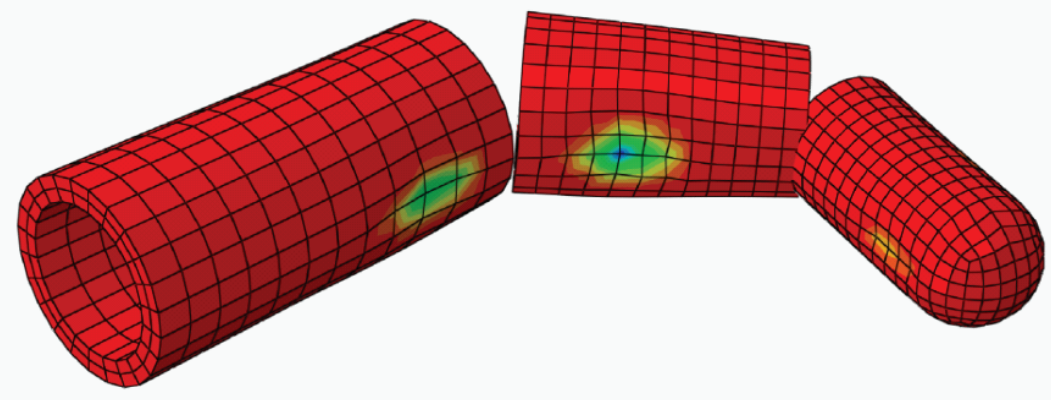

(c) $44 \mathrm{~mm}$ diameter handle

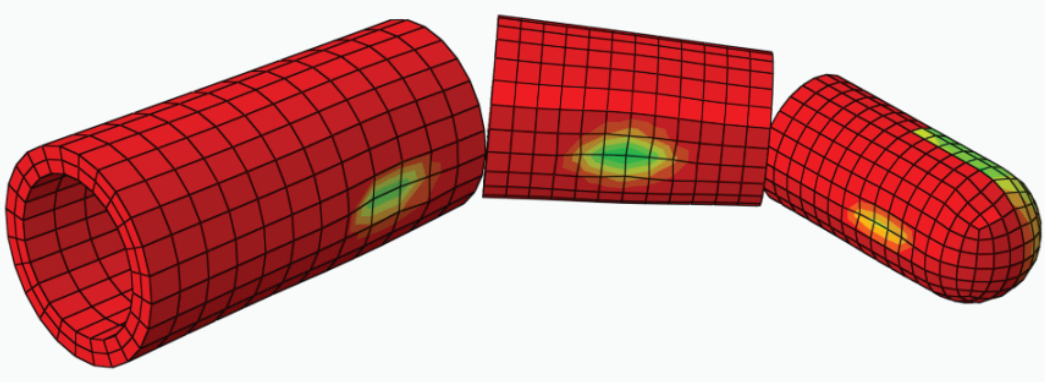

(d) $50 \mathrm{~mm}$ diameter handle

Fig. 2. Maximal compressive stresses in soft skin for various diameters handle with $10 \mathrm{~N}$ grip force (a) $30 \mathrm{~mm}$ diameter handle, (b) $40 \mathrm{~mm}$ diameter handle, (c) $44 \mathrm{~mm}$ diameter handle, (d) $50 \mathrm{~mm}$ diameter handle 


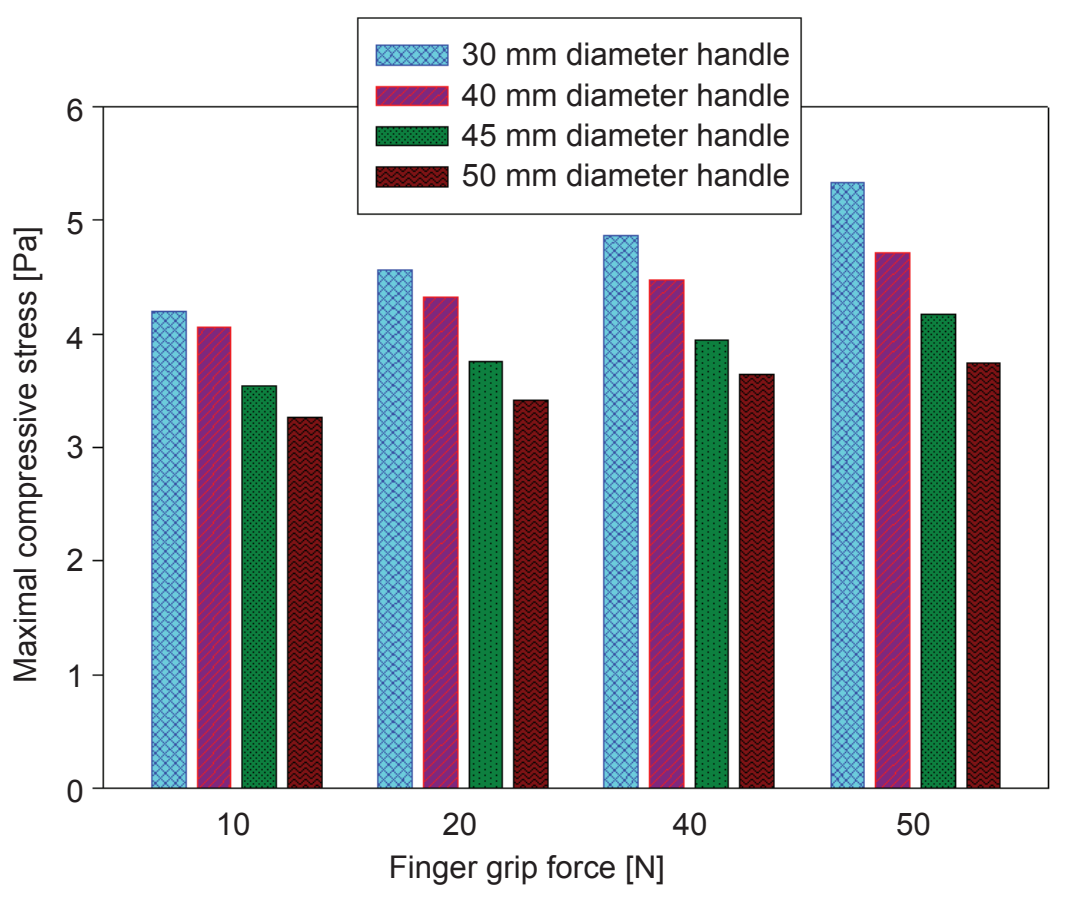

Fig. 3. Maximal compressive stresses on the soft skin while gripping various diameter handles with different grip force (Pa)

skin of the finger gripping handles of various diameters. It is seen that the maximal compressive stresses decreased with increasing handle diameter (Fig. 2). Stresses were observed in all the three segments (proximal, middle and distal) during the hybrid finger model gripping at $30 \mathrm{~mm}$, $44 \mathrm{~mm}$ and $50 \mathrm{~mm}$ diameter handles.

The maximal compressive stress for $10 \mathrm{~N}$ grip force was found to be 4.2 $\mathrm{Pa}, 4.06 \mathrm{~Pa}, 3.5 \mathrm{~Pa}$ and 3.2 $\mathrm{Pa}$ for $30 \mathrm{~mm}, 40 \mathrm{~mm}, 44 \mathrm{~mm}$ and $50 \mathrm{~mm}$ diameter cylinders, respectively, as shown in Figure 3. However, the distribution of maximal compressive stress was not found in the distal segment during $10 \mathrm{~N}$ grip force applied on the $40 \mathrm{~mm}$ diameter handle. For $20 \mathrm{~N}$ grip force the maximal compressive stress was found to be $4.56 \mathrm{~Pa}, 4.321 \mathrm{~Pa}$, 3.76 $\mathrm{Pa}$ and $3.41 \mathrm{~Pa}$ for respective cylindrical diameter handles. Similarly, the maximal compressive stress on the soft skin of the finger response is shown in Figure 3 for $40 \mathrm{~N}$ and $50 \mathrm{~N}$ grip forces. The results indicate that the compressive stress increases with respect to the grip force and at the same time the results suggest that the stresses in the soft tissues can be reduced by considering the handle diameter. The contact area between the finger and handles increases, and thereby the compressive stress decreases. The obtained results were in good agreement with the previous results obtained by Wu et al. [33] for a hybrid finger model gripping various stiffness materials with various grip forces.

The simulation results of maximal compressive strain on the soft tissues, when the finger model is subjected to $10 \mathrm{~N}$ grip force of various diameters, are shown in Fig. 4 (a, b, c, d). The maximal compressive strain varies with respect to the handle diameter similar to the compressive stress. From Figure 5, the maximal compressive strain for $10 \mathrm{~N}$ was found to be $0.018,0.017,0.014$ and 0.012 for $30 \mathrm{~mm}, 40 \mathrm{~mm}, 44 \mathrm{~mm}$ and $50 \mathrm{~mm}$ diameter cylinders respectively. Similarly the maximal compressive strain on the soft skin of the finger response is shown in Figure 5 for $20 \mathrm{~N}, 40 \mathrm{~N}$ and $50 \mathrm{~N}$ grip forces. Similar to the compressive stress, the compressive strain also decreased with the increase in the handle diameters due to the increase in the contact area between the finger and the handles. Also, the simulation results recommend that the compressive strain increases with respect to the increase in grip forces. The highest magnitude of stresses and strains is indicated with blue in the figures.

The simulation results of contact pressures for the finger model subject to grip with $10 \mathrm{~N}$ force of various diameters are shown in Figure 6. The pressure distribution on the cylindrical handle by the proximal, middle and distal phalanges is shown in the below Figures 6. The results from the CPRESS provide the peak contact pressure of the finger model.

The contact pressure varies with respect to the diameter of the handles. The simulation results suggest that the maximal contact pressure was obtained at the middle segment. From Figure 7, it can be seen that the contact pressure was reduced from $2.126 \mathrm{e}+05 \mathrm{~Pa}$ to $1.562 \mathrm{e}+05 \mathrm{~Pa}$ for the $30 \mathrm{~mm}$ diameter handle to the $50 \mathrm{~mm}$ diameter handle respectively. Similarly, the contact pressure on the soft skin of the finger response is shown in Figure 7 for $20 \mathrm{~N}$, 

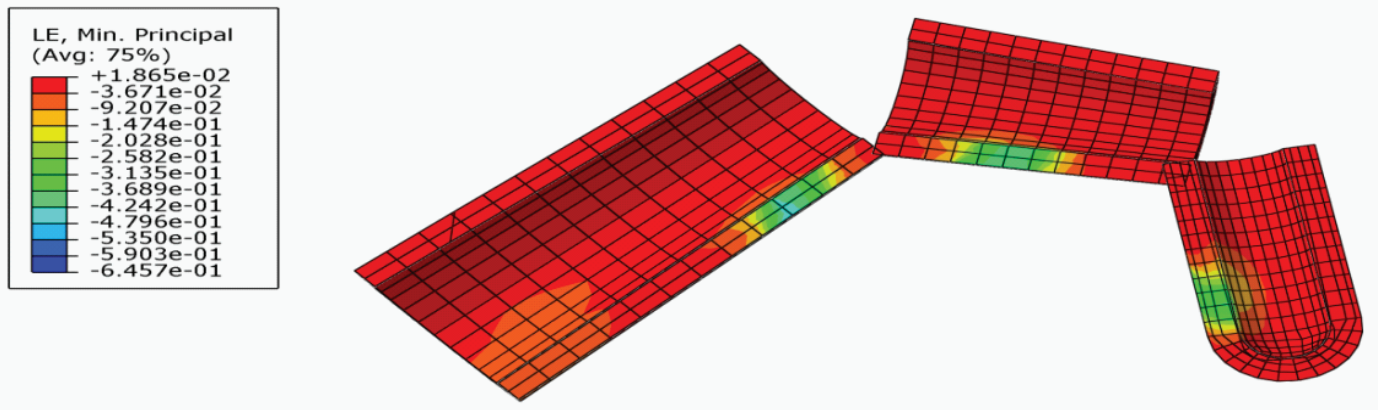

(a) $30 \mathrm{~mm}$ diameter handle
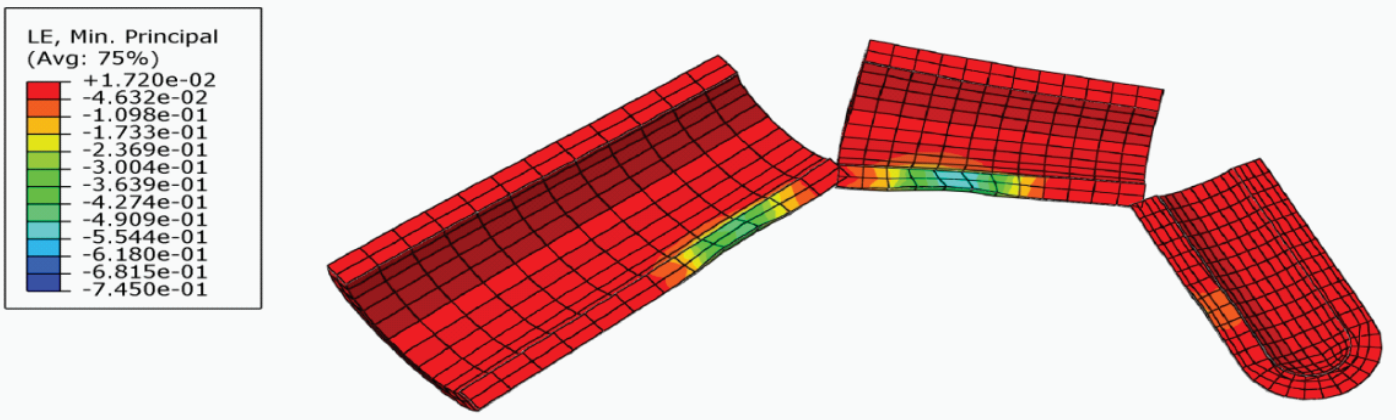

(b) $40 \mathrm{~mm}$ diameter handle
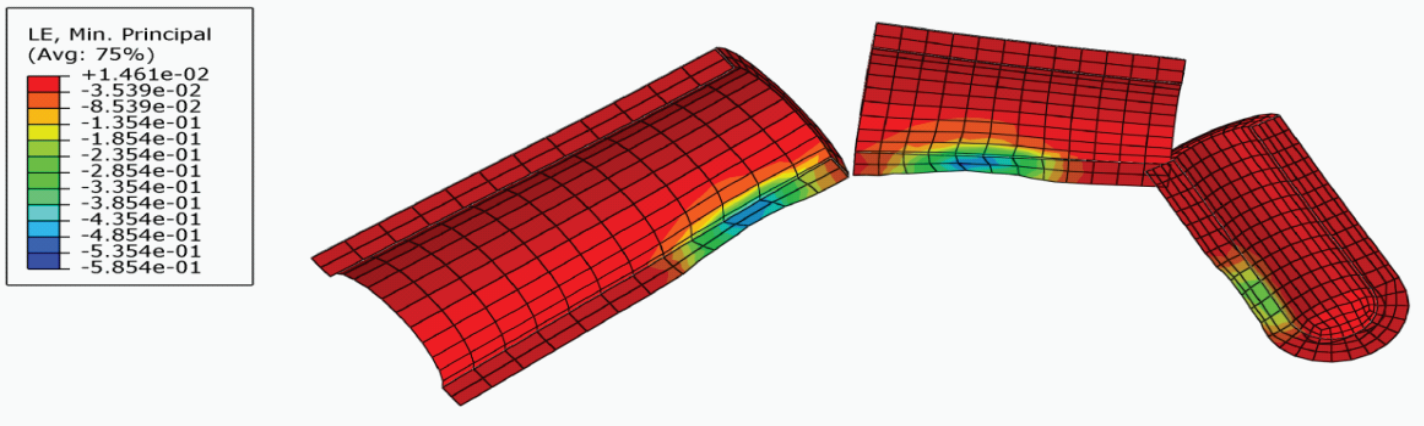

(c) $44 \mathrm{~mm}$ diameter handle
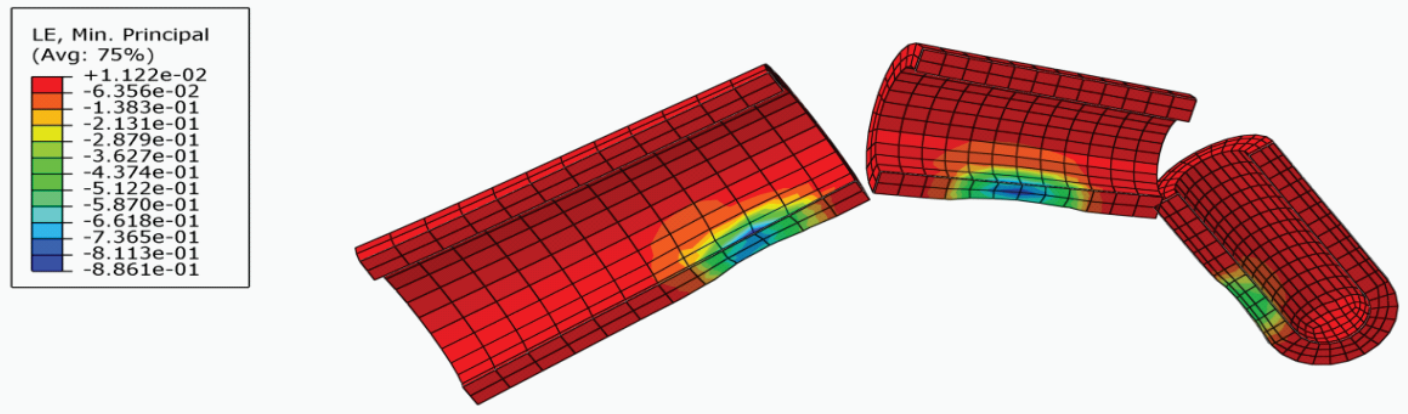

(d) $50 \mathrm{~mm}$ diameter handle

Fig. 4. Maximal compressive strains in soft skin for various diameters handle with $10 \mathrm{~N}$ grip force. (a) $30 \mathrm{~mm}$ diameter handle, (b) $40 \mathrm{~mm}$ diameter handle, (c) $44 \mathrm{~mm}$ diameter handle, (d) $50 \mathrm{~mm}$ diameter handle 


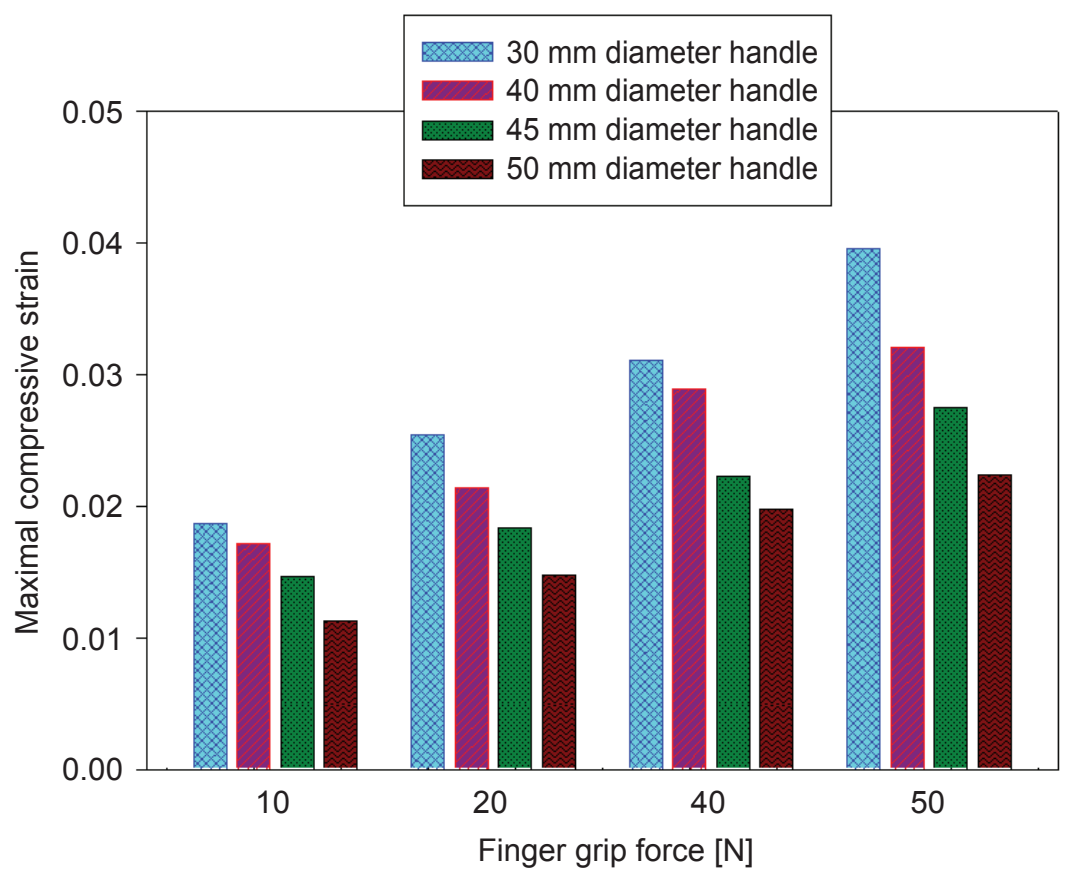

Fig. 5. Maximal compressive strain on the soft skin while gripping various diameter handles with different grip force
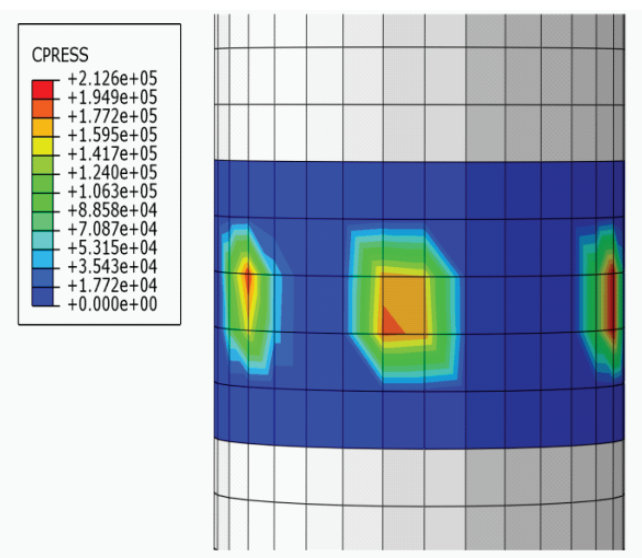

(a) $30 \mathrm{~mm}$ diameter handle
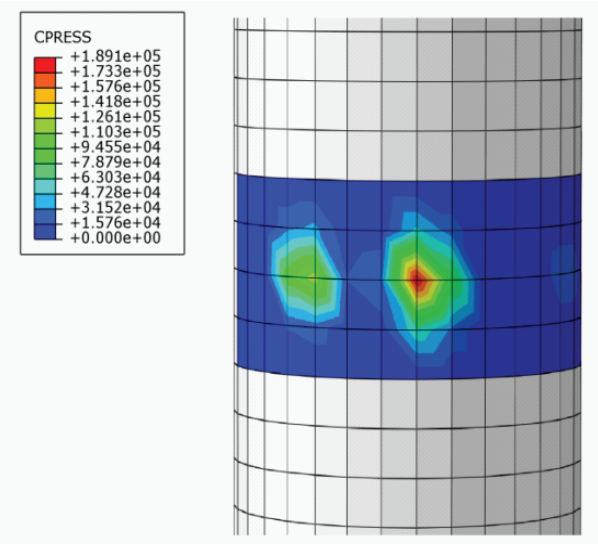

(c) $44 \mathrm{~mm}$ diameter handle
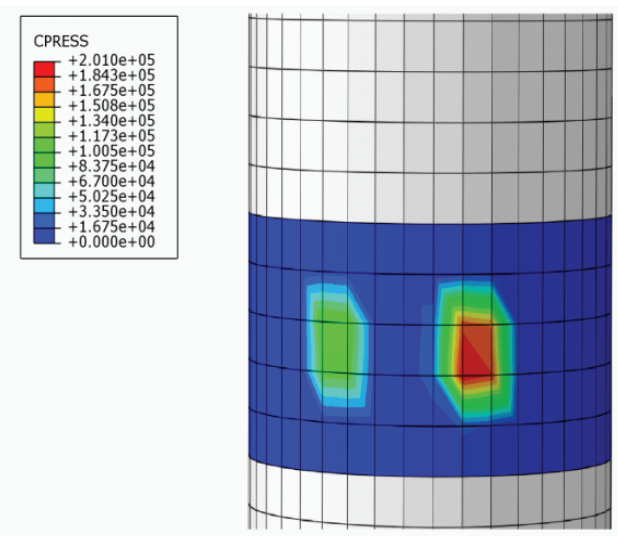

(b) $40 \mathrm{~mm}$ diameter handle
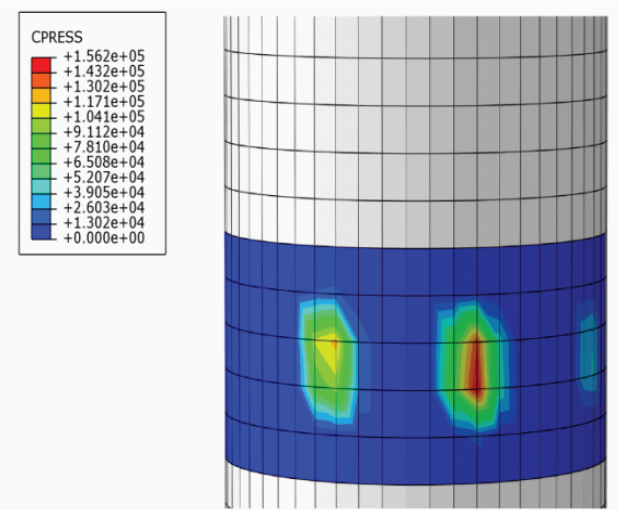

(d) $50 \mathrm{~mm}$ diameter handle

Fig. 6. Distribution of contact pressure on soft skin for various diameters handles with $10 \mathrm{~N}$ grip force 


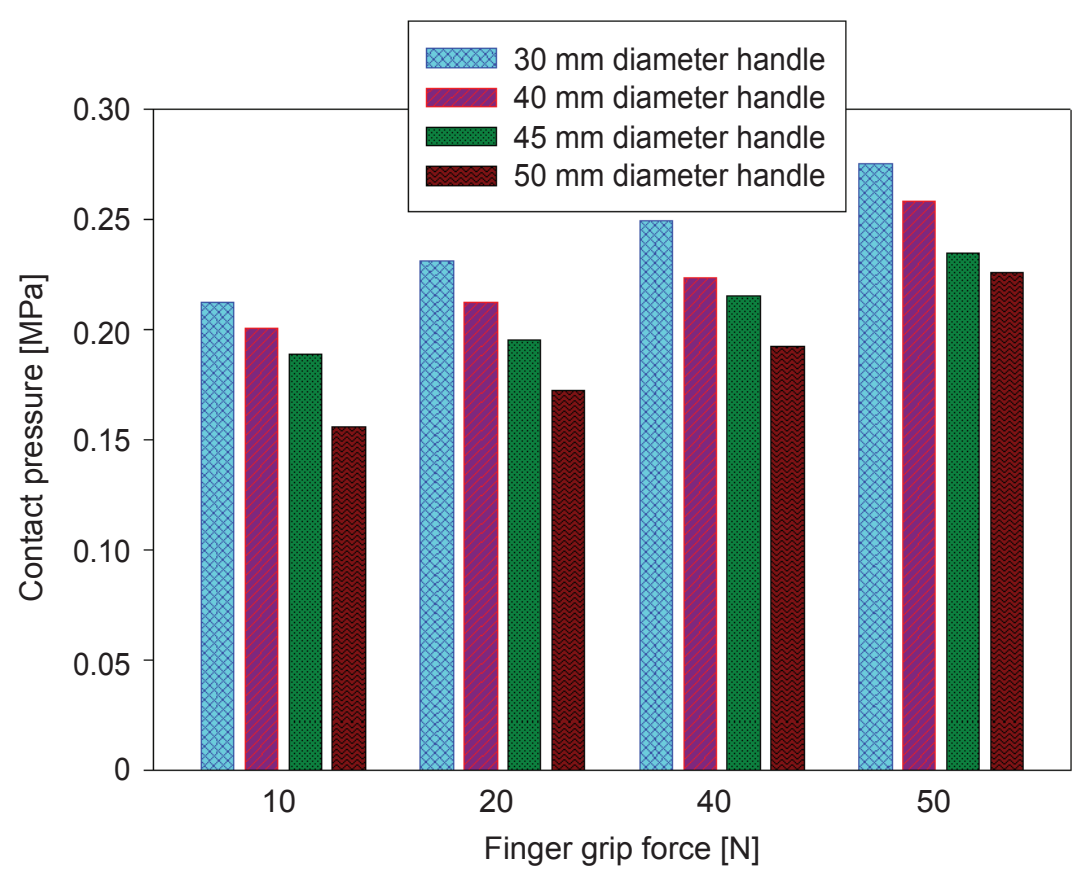

Fig. 7. Contact pressure on the soft skin while gripping various diameter handles with different grip force

$40 \mathrm{~N}$ and $50 \mathrm{~N}$ grip forces. It is perceived that the contact pressure decreases and contact area increases when the diameter of handles varies from $30 \mathrm{~mm}$ to $50 \mathrm{~mm}$. The results show that the contact pressure varies depending on the design, size, material and diameter of the handles. The contact pressure analysis obtained is in good agreement with the experimental values [34]. The interaction between the finger model and handle plays a major role in the pressure development in each segment.

An increase in the grip force also may increase the contact pressure in all three segments. From the simulation results, the maximal compressive stress/strain and maximal contact pressure were observed in the middle segment, whereas the minimal compressive stress/strain and minimal contact pressure were observed in the distal segment.

\section{Discussion}

A handle is an interface between the hand and tools. It is important to consider the comfort of the operator to increase the efficiency of the work, thereby avoiding fatigue and injuries. The important factors that affect the interface between the hand and handle are the curvatures of the handles and the diameters of the handles. As shown by the experimental studies, handle diameter and curvature of the handle diameter influence the strength [13] of the grip and stability [19].

The maximal compressive stress on the finger skin was reduced by $23 \%$ during the $10 \mathrm{~N}$ grip force while the diameter of the handles varied from $30 \mathrm{~mm}$ to $50 \mathrm{~mm}$.
Similarly, the compressive stress was reduced by $24.6 \%$, $25 \%$ and $39.6 \%$, while the diameter of the handles varied from $30 \mathrm{~mm}$ to $50 \mathrm{~mm}$ during $20 \mathrm{~N}, 40 \mathrm{~N}$ and $50 \mathrm{~N}$ respectively. Experimental work carried out by Alphin et al. [3] with various diameter handles showed that the minimum vibration transmissibility occurred at the wrist, elbow and shoulder for maximum diameter handles. But the trend varies, since an increase in grip force increases the compressive stress in the finger soft skin model. Maximal compressive stress was increased by $21 \%$ for the $30 \mathrm{~mm}$ diameter handle while the grip force was increased from $10 \mathrm{~N}$ to $50 \mathrm{~N}$ simultaneously. Likewise, the compressive stress was increased by $13 \%, 15 \%$ and $13 \%$ for $40 \mathrm{~mm}$, $45 \mathrm{~mm}$ and $50 \mathrm{~mm}$ diameter handles, respectively, while the grip force was increased from $10 \mathrm{~N}$ to $50 \mathrm{~N}$.

In the present analysis, the maximal compressive strain was influenced significantly by the diameter variations of the handles. Within a range of handle diameter from $30 \mathrm{~mm}$ to $50 \mathrm{~mm}$ the compressive strain decreased when the diameter of the handle increased. The maximal compressive strain on the finger skin decreased by $40 \%$, $41.7 \%, 36 \%$ and $43.4 \%$, while the diameter of the handle varied from $30 \mathrm{~mm}$ to $50 \mathrm{~mm}$ during $10 \mathrm{~N}, 20 \mathrm{~N}, 40 \mathrm{~N}$ and $50 \mathrm{~N}$ respectively. Similar to the compressive stress, compressive strain also decreased while the diameter of the handle increased. But the compressive strain increased with respect to the increase in the grip force for the same handle diameter. The maximal compressive strain was increased by $52.7 \%, 46 \%, 47 \%$ and $50 \%$, while the grip force was increased from $10 \mathrm{~N}$ to $50 \mathrm{~N}$ for $30 \mathrm{~mm}, 40 \mathrm{~mm}$, $45 \mathrm{~mm}$ and $50 \mathrm{~mm}$ handles diameters respectively. 
Contact pressure on the finger model also has a similar response as like compressive stress and strain. Again, from the simulation results it is seen that the contact pressure decreases with the increase in the contact area. The increase in the contact area between the hand and handle reduces the contact pressure and prevents the excessive stress/strain transferred to the human hand-arm system [18]. The contact pressure was reduced by $26.5 \%, 25.4 \%$, $22.8 \%$ and $18 \%$, while the diameter increased from $30 \mathrm{~mm}$ to $50 \mathrm{~mm}$ during forces of $10 \mathrm{~N}, 20 \mathrm{~N}, 40 \mathrm{~N}$ and $50 \mathrm{~N}$ respectively. In all the cases, the typical contact pressure and contact area increased for the same diameter handle with an increase in the load. The contact pressure was increased by $22.8 \%, 22 \%, 19.4 \%$ and $30.8 \%$, while the grip force was increased from $10 \mathrm{~N}$ to $50 \mathrm{~N}$ for $30 \mathrm{~mm}, 40 \mathrm{~mm}$, $45 \mathrm{~mm}$ and $50 \mathrm{~mm}$ respectively. Several studies indicate that the discomfort in the hand is associated with interaction between the hand and the handle, and also the concentration of the contact pressure $[7,10,24]$. The present study recommends that the compressive stress, compressive strain and contact pressure on the finger can be reduced by considering the diameter of the handles. The simulation results imply that the comfort of the operator depends on the diameter of the handles.

\section{Conclusions}

In the present study, the contact interactions between the FE finger model and cylindrical handles with different diameters were analyzed using finite element analysis.

- The different diameter of the handles was found to influence the distributions of maximal compressive stress, maximal compressive strain and contact pressure within the FE finger model.

- Simulation results suggest that for the same grip force, increase in handle diameters reduces the maximal compressive stress/strain and contact pressure and at the same time, for the same diameter handle, increase in grip forces increases the maximal compressive stress/strain and contact pressure in the finger model.

- The simulation results from the present study will be useful for ergonomic designers to avoid risks for the hand, by reducing fatigue and increasing the comfort for the fingers.

\section{Conflict of interest: Authors state no conflict of interest.}

\section{References}

1. Adams S.K., Peterson P.J. (1990) Maximumvoluntary hand grip torque for circular electrical connectors. Appl. Ergon., 21: 78-79.
2. Agache P.G., Monneur C., Leveque J.L., De Rigal J. (1989) Mechanical proper - ties and Young's modulus of human skin in vivo. Arch. Dermatol. Res., 269: 32-221.

3. Alphin M.S., Sankaranarayanasamy K., Sivapirakasam S.P. (2013) Experimental investigation to study the influence of handle diameter on low-frequency, handarm vertical vibration. Hum. Factors. Ergon. Manuf., 23: 140-148.

4. Athanasiou K.A., Rosenwasser M.P., Buckwalter J.A., Malinin T.I., Mow V.C. (1991) Inter-species comparisons in in situ intrinsic mechanical properties of distal cartilage. J. Orthop. Res., 9: 330-340.

5. Baran R. (2004) Nail anatomy and physiology. In: Agache P., Humbert P. (eds.) Measuring the skin', Berlin, Heidelberg: Springer-Verlag, pp. 3-290.

6. Bjoring G., Johansson L., Hagg G. (1999) Choice of handle characteristics for pistol grip power tools. Int. J. Ergon., 24: 647-656.

7. Bovenzi M. (1988) Vibration white finger, digital blood pressure, and some biochemical findings on workers operating vibrating tools in the engine manufacturing industry. Am. J. Ind. Med., 14: 575-584.

8. Brook N., Mizrahi J., Shoham M., Dayan J. (1995) A biomechanical model of index finger dynamics. Med. Eng. Phys., 17: 54-63.

9. Daly C.H. (1982) Biomechanical properties of dermis', J. Investig. Dermatol., 79: 17-20.

10. Ekenvall L., Lindblad L.E. (1986) Vibration white finger and digital systolic pressure during cooling. Br. J. Ind. Med., 43: 280-283.

11. Eksioglu M. (2004) Relative optimum grip span as a function of hand anthropometry. Int. J. Ind. Ergonom., 34: $1-12$.

12. Fransson C., Winkel J. (1991) Hand strength: the influence of grip span and grip type. Ergon., 34: 881-892.

13. Freund J., Toivonen R., Takala E.P. (2002) Grip forces of the fingertips. Clin. Biomech. (Bristol, Avon.), 17: 515-520.

14. Grant K.A., Habes D.J., Stewart L.L. (1992) An analysis of handle designs for reducing manual the influence of grip diameter. Int. J. Ind. Ergon., 10: 199-206.

15. Harih G., Dolšak B. (2014) Recommendations for toolhandle material choice based on finite element analysis. Appl. Ergon., 45: 577-585.

16. Imrhan S.N., Farahmand K. (1999) Male torque strength in simulated oil rig tasks: the effects of grease-smeared gloves and handle length, diameter and orientation. Appl. Ergon., 30: 455-462.

17. Imrhan S.N., Sundararajan K. (1992) An investigation of finger pull strengths. Ergon., 35: 289-299.

18. Jain A.R. Tony B., Alphin M.S. (2018) Assessment of ergonomically designed handle shapes for low-frequency vibration responses. Proc. Inst. Mech. Eng. Pt. L, J. Mater. Des. Appl., DOI: 10.1177/1464420718766961. 
19. Jenmalm P., Goodwin A.W., Johansson R.S. (1998) Control of grasp stability when humans lift objects with different surface curvatures. J. Neurophysiol., 79: 1643-1652.

20.Kong Y.K., Freivalds A. (2003) Evaluation of meat hook handle shapes. Int. J. Ind. Ergon., 32: 13-23.

21. Kong Y.K., Lowe B.D., Lee S.J., Krieg E.F. (2008) Evaluation of handle shapes for screw driving. Appl. Ergon. 39: 191-8.

22. Marras W.S., Cutlip R.G., Burt S.E., Waters T.R. (2009) National occupational research agenda (nora) future directions in occupational musculoskeletal disorder health research. Appl. Ergon., 40: 15-22.

23. Marvik R., Nesbakken R., Lango T., Yavuz Y., Vanhauwaert Bjelland H., OttermoM.V., Stavdahl O. (2006) Ergonomic design criteria for a novel laparoscopic tool handle with tactile feedback. Minerva. Chir., 61: 435-44.

24. Nerem R. (1977)Vibration enhancement of blood-arterial finger wall macromolecule transport. In International Hand-Arm Vibration Conference, Cincinnati, USA, pp. 37-41.

25. Pheasant S., O’Neill D. (1975) Performance in gripping and turning - a study in hand/handle effectiveness. Appl. Ergon., 6: 205-208.

26. Sancho-Bru J.L., Perez-Gonzalez A., Vergara-Monedero M., Giurintano D. (2001) A 3-D dynamic model of human finger for studying free movements. J. Biomech., 34: 1491-1500.

27. Savescu A.V., Latash M.L., Zatsiorsky V.M. (2008) A technique to determine friction at the fingertips. $J$. Appl. Biomech., 24(1): 43-50.

28. Schulter-Ellis F.P., Lazar G.T. (1984) Internal morphology of human phalanges. J. Hand. Surg., 9: 5-490.

29. Seo N.J., Armstrong T.J., Chaffin D.B., Ashton-Miller J.A. (2008) The effect of handle friction and inward or outward torque on maximum axial push force. Hum. Factors., 50: 227-236.

30. Seo N.J., Armstrong T.J., Ashton-Miller J.A., Chaffin D.B. (2008) Wrist strength is dependent on simultaneous power grip intensity. Ergon., 51: 1594-1605.

31. Valero-Cuevas F.J., Zajac F.E., Burgar C.G. (1998) Large index-fingertip forces are pro-duced by subject-inde- pendent patterns of muscle excitation. J. Biomech., 31: 693-703.

32. Wu J.Z., Cutlip R.G., Welcome D., Dong R.G. (2006) Estimation of the viscous properties of skin and subcutaneous tissue in uniaxial stress relaxation tests. Bio Med. Mater. Eng., 16: 53-66.

33. Wu J.Z., Dong R.G., Christopher M.W., Welcome D.E., Thomas W.M. (2014) Analysis of the effects of surface stiffness on the contact interaction between a finger and a cylindrical handle using a three-dimensional hybrid model. Med. Eng. Phys., 36: 831-841.

34. Wu J.Z., Dong R.G., Rakheja S., Schopper A.W. (2002). Simulation of mechanical responses of fingertip to dynamic loading. Med. Eng. Phys., 24: 253-264.

35. Wu J.Z., Krajnak K., Welcome D.E., Dong R.G. (2006). Analysis of the dynamic strains in a fingertip exposed to vibrations: correlation to the mechanical stimuli on mechanoreceptors. J. Biomech., 39: 2445-2456.

36. Wu J.Z., Welcome D.E., Dong R.G. (2006) Three-dimensional finite element simulations of the mechanical response of the fingertip to static and dynamic compressions. Comput. Methods Biomech. Biomed. Eng., 9: $55-63$.

37. Wu J.Z., Welcome D.E., Krajnak K., Dong R.G. (2007) Finite element analysis of the penetrations of shear and normal vibrations into the soft tissues in a fingertip. Med. Eng. Phys., 29:718-727.

38. Yamada H. (1970) Strength of biological materials', Baltimore: Williams and Wilkins Co.

\section{Received 27.09.2018 \\ Accepted 02.04.2019}

@ University of Physical Education, Warsaw, Poland

Acknowledgments

This research work was supported by the grant of Department of Science and Technology (DST, India) Reference No. YSS/2014/000715. 